\title{
Precise NMR Method for Titering Organometal Reagents
}

\author{
Vineet K. Jakhar, a Eric C. Johnson, b Aditya Kavuturu, a Jessica K. Heller, a Adam S. Veige, a and Ion \\ Ghiviriga ${ }^{a *}$ \\ a Department of Chemistry, University of Florida, Gainesville, Florida 32611-7200, United States \\ b Bruker Biospin, 61 Daggett Drive, San Jose, California 95134, United States
}

\section{Table of Contents:}

1.1. General procedures. .2

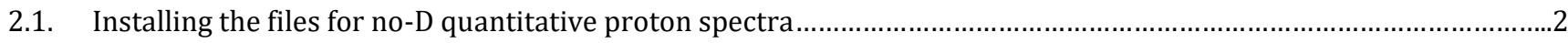

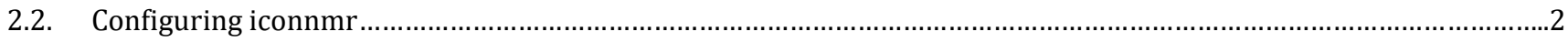

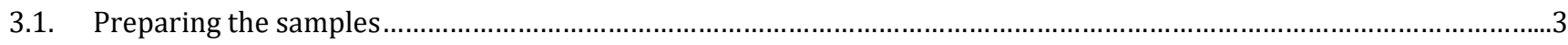

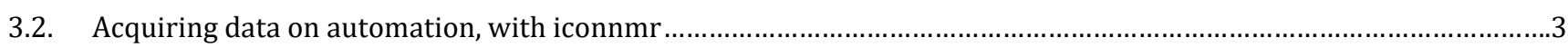

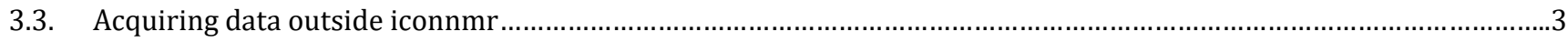

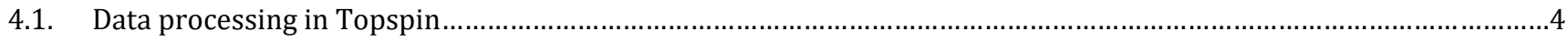

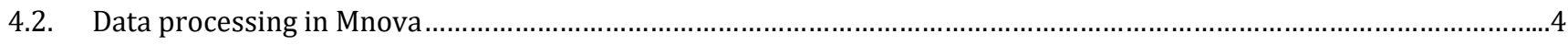

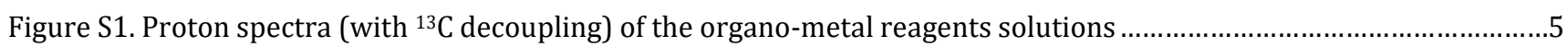

Table S1. Concentrations of neat solvents measured using water as external reference ..................................................

Table S2. Average and standard deviation of the concentration neat solvents using water as external reference ................8

Table S3. Average and standard deviation of the concentration of $n$-BuLi $2.5 \mathrm{M}$ in hexanes............................................

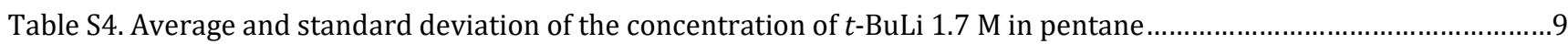

Table S5. Average and standard deviation of the concentration of LDA $1 \mathrm{M}$ in THF/hexanes ..........................................

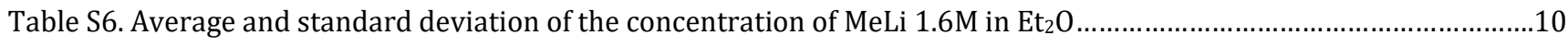

Table S7. Average and standard deviation of the concentration of EtLi 0.5 M in benzene/cyclohexane..............................10

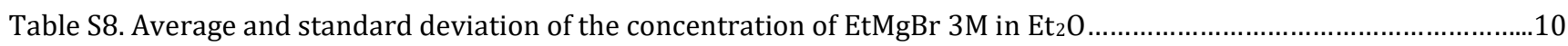

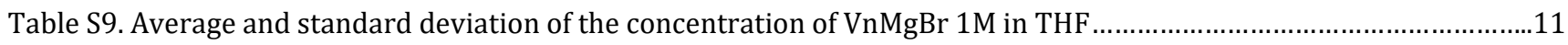

Table S10. Average and standard deviation of the concentration of AllylMgCl 2M in THF ...........................................11

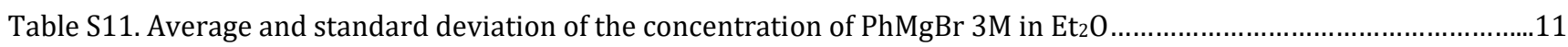

Table S12. Measured concentration of dioxane in toluene in samples prepared by subsequent dilutions of dioxane with an

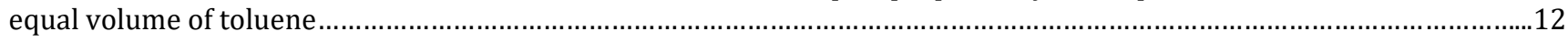

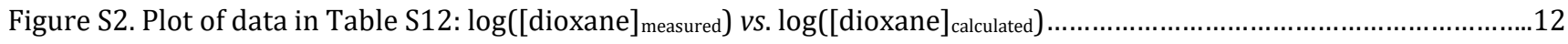

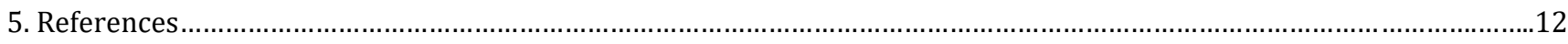




\section{General Procedures}

The organometal reagents were purchased from Acros Organics ( $n$-BuLi 2.5 M in hexanes, lot no. Ao416082) and SigmaAldrich ( $t$-BuLi 1.7 M in pentane, batch no. SHMB 1896; LDA 1.0 M in THF/hexanes lot no. SHBL 0365; MeLi 1.6 M in diethyl ether, batch no. SHBG 1030V; EtLi 0.5 M in benzene/cyclohexane, lot no. SHBC 6643; EtMgBr $3.0 \mathrm{M}$ in diethyl ether, batch no. SHBF 5937V; VinylMgBr 1.0 M in THF, batch no. SHBL 9606; AllylMgCl $2.0 \mathrm{M}$ in THF, batch no. SHBL3301 and PhMgBr 3.0 M in diethylether, batch no. SHBJ 3942).

NMR spectra were acquired on automation on a Bruker Avance HDIII spectrometer operating at $600 \mathrm{MHz}$ for proton and equipped with a $5 \mathrm{~mm}$ Smart probe and a 24 chutes sample changer. The setup outside automation was tested on a Bruker Avance HDIII spectrometer operating at $400 \mathrm{MHz}$ for proton and equipped with a $5 \mathrm{~mm}$ Smart probe.

\subsection{Installing the files for no-D quantitative proton spectra}

Download the $H Q$ directory.

Copy calib1hpw90_v5.ecj into topspinhome/exp/stan/nmr/au/src/user/calib1jpw90_v5.ecj.

Copy zg2d_calibp1.ecj into topspinhome/exp/stan/nmr/lists/pp/user/zg2d_calibp1.ecj

Open the pars directory and copy noD-hq into topspinhome/exp/stan/nmr/par/user/directory.

On the instrument, login as nmrsu.

In topspin, type paracon, select the parameters set you downloaded in the user directory and click Execute. This will update the parameter set with the frequency of your spectrometer.

Create a new dataset with the noD-hq parameters. Type getprosol. This will update the parameter set with the power levels and pulse durations on your spectrometer.

Type wpar and overwrite the noD-hq.

\subsection{Configuring iconnmr}

Login as nmrsu. Start iconnmr.

Go to Options / Configuration / User Manager and select a user.

In the right panel select an experiment; this opens the experiment entry box. Move the Source Directory to_topspinhome/exp/stan/nmr/par/user and in the drop-down Experiment Name select noD-hq. Click Append then Close. Under Permissions allow the user to Edit Lock/Shim/ATM. Click Save at the bottom of the window.

In the Options / Configuration / move down to Automation / Tunning/Matching, select the noD-hq experiment at the bottom of the list and right-click to change the tunning/matching on both the $\mathrm{H}$ and the $\mathrm{X}$ channels to a $\mathrm{l}-$ ways.

In the File at the top of the Configuration Menu click Save and Update Run Parameters then Close. 


\subsection{Preparing the samples}

Use tubes from the same manufacturer lot. Alternately, use the water standard to measure the water concentration in the tubes you want to use. If the error is more than $0.4 \%$, calculate a tube factor. Dry tubes in the oven at $100{ }^{\circ} \mathrm{C}$ for several hours.

To prepare the water standard, fill one tube with tap water, then flame-seal it and label it. To prepare the reagent sample, use a syringe to transfer the organo-metal reagent from the bottle into the NMR tube. Cap the tube and Parafilm it.

Caution: Handle the organo-metal reagents in a properly ventilated fume hood or inside the Glovebox.

\subsection{Acquiring data on automation, with iconnmr}

Place the tube with the water reference in the first holder. Input the Disk, Name and Solvent information,

From the drop-down experiment list, select noD-hq.

Click on Control Locking, Shimming and ATM icon, four boxes to the right. Set Lock Program to LOCK-OFF. In the Shim Program type TOPSPIN 1h lockoff $\mathbf{0 1 p = 4 . 3 4}$ selwid=0.5. Shimming will be done on the shape of the water line at $4.34 \mathrm{ppm}$. Verify that tuning and matching is set to yes on both the ${ }^{1} \mathrm{H}$ and $\mathrm{X}$ channels.

\section{Click Submit.}

Use the subsequent holders to place the tubes filled with solutions of organo-metal reagents directly from the bottle. Set up the experiments as for the water sample above, or better Copy it, with the only difference that the value of o1p is that corresponding to the solvent, in Table S1. For the hexanes mixture, $\mathrm{o} 1 \mathrm{p}=1.38$.

\subsection{Acquiring data outside iconnmr}

Make sure that in Topspin under Manage / Preferences /Administration items the Enable automatic command spooling is checked on.

Load your sample, water reference or organo-metal analyte.

Create a new dataset as usual, loading noD-hq parameters.

In the command line type qu lock off; qu topshim 1h lockoff o1p=4.34 selwid=0.5; qu xaua;

The position of the signal to shim on for water is at $4.34 \mathrm{ppm}$; for other solvents see Table S1. 


\subsection{Data Processing in Topspin}

In the water reference data set:

Do the exponential multiplication of the FID, the Fourier transform and the automated phase correction: efp $\longleftrightarrow$; apk $\longleftrightarrow$.

Apply a $5^{\text {th }}$ order polynomial baseline correction: abs 4 . This will also define the integral around the water signal.

Go to Analyse - Integrate and right-click on the integral. From the drop-down menu go to Eretic - Define as Eretic Reference. Set the concentration [mmol/l] to 55346 and the number of atoms to 2. Click OK, then exit the integration interface by pressing Return, save regions.

In the data set for the organo-metal reagent (e.g. $n$-BuLi in hexanes):

Transform the FID with efp 4 ; Go to Process - Adjust Phase, press on 0 and drag up or down until the sides of the signal under the cursor are balanced. Do the same by pressing on 1 to balance the sides of the signals remote from the cursor, particularly the signal in the negative ppm. Exit by clicking Return and save phased spectrum. Type abs $\mathbf{n} \ll$ to apply a fifth order baseline correction, but without defining integrals in the spectrum.

Go to Analyse - Integrate. Define an integral around the $\alpha$-methylene protons in $n$-BuLi, the signal around -0.2 to $0.8 \mathrm{ppm}$, then right-click on the integral. From the drop-down menu go to Eretic - Calculate Concentration. Define the number of atoms as 2, then click OK. The ERETIC module uses the PULCON relationship to calculate the concentration, which is then displayed on the spectrum.

If you need to redo the calculation, delete the eretic files in the processes of the two data sets. Best to do this with the search feature in Windows Explorer.

\subsection{Data processing in Mnova}

Mnova does not have an implementation of the PULCON relationship; therefore, the calculations must be done manually in an Excel sheet.

Open the water standard dataset. Click Shift-P and drag up and down holding the left mouse button (LMB) to correct for the zero-order phase and then the right mouse button (RMB) to correct for the first-order phase. Type $\mathbf{B}$ and select a $5^{\text {th }}$ order polynomial for baseline correction.

Type I and define a large integral around the water signal, e.g. 8 to $2 \mathrm{ppm}$. Press esc and right-click on the integral to open the edit integral menu. Write down the value of the absolute integral (AI) in Excel.

From the top menu drag down View - Tables and in Common check parameters. From the window that opens read the value of Pulse Width and enter it in the Excel sheet.

Open the organo-metal reagent file, e.g. $n$-BuLi. Adjust phasing and do the baseline correction, as before. Define an integral from 0.5 to $-1.5 \mathrm{ppm}$. Transfer the values of the absolute intensity and pulse width to the Excel sheet.

In Excel calculate the concentration of the organo-metal reagent using PULCON:

[analyte $]=\left(\mathrm{A}_{\text {analyte }} / \mathrm{NS}_{\text {analyte }}\right) /\left(\mathrm{A}_{\text {reference }} / \mathrm{NS}_{\text {reference }}\right) \times\left(\mathrm{pw} 90_{\text {analyte }} / \mathrm{pw} 90_{\text {reference }}\right) \times[$ reference $]$

\begin{tabular}{|c|c|c|c|c|c|c|c|}
\hline \multicolumn{2}{|c|}{ C5 } & \multirow{2}{*}{ 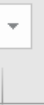 } & \multirow{2}{*}{ B } & \multicolumn{2}{|c|}{$\vee \quad \vee \quad f_{x}$} & \multicolumn{2}{|c|}{$=(\mathrm{C} 2 / \mathrm{C} 4) /(\mathrm{B} 2 / \mathrm{B} 4)^{*} \mathrm{~B} 5$} \\
\hline$\Delta$ & A & & & C & D & $E$ & $\mathrm{~F}$ \\
\hline 1 & & & ater & nBuLi & & & \\
\hline 2 & $\mathrm{Al}$ & & 302726 & 13749 & & & \\
\hline 3 & PW & & 10.05 & 10.06 & & & \\
\hline 4 & NS & & 2 & 2 & & & \\
\hline 5 & [conc.] & & 55.3458 & 2.513657 & & & \\
\hline
\end{tabular}



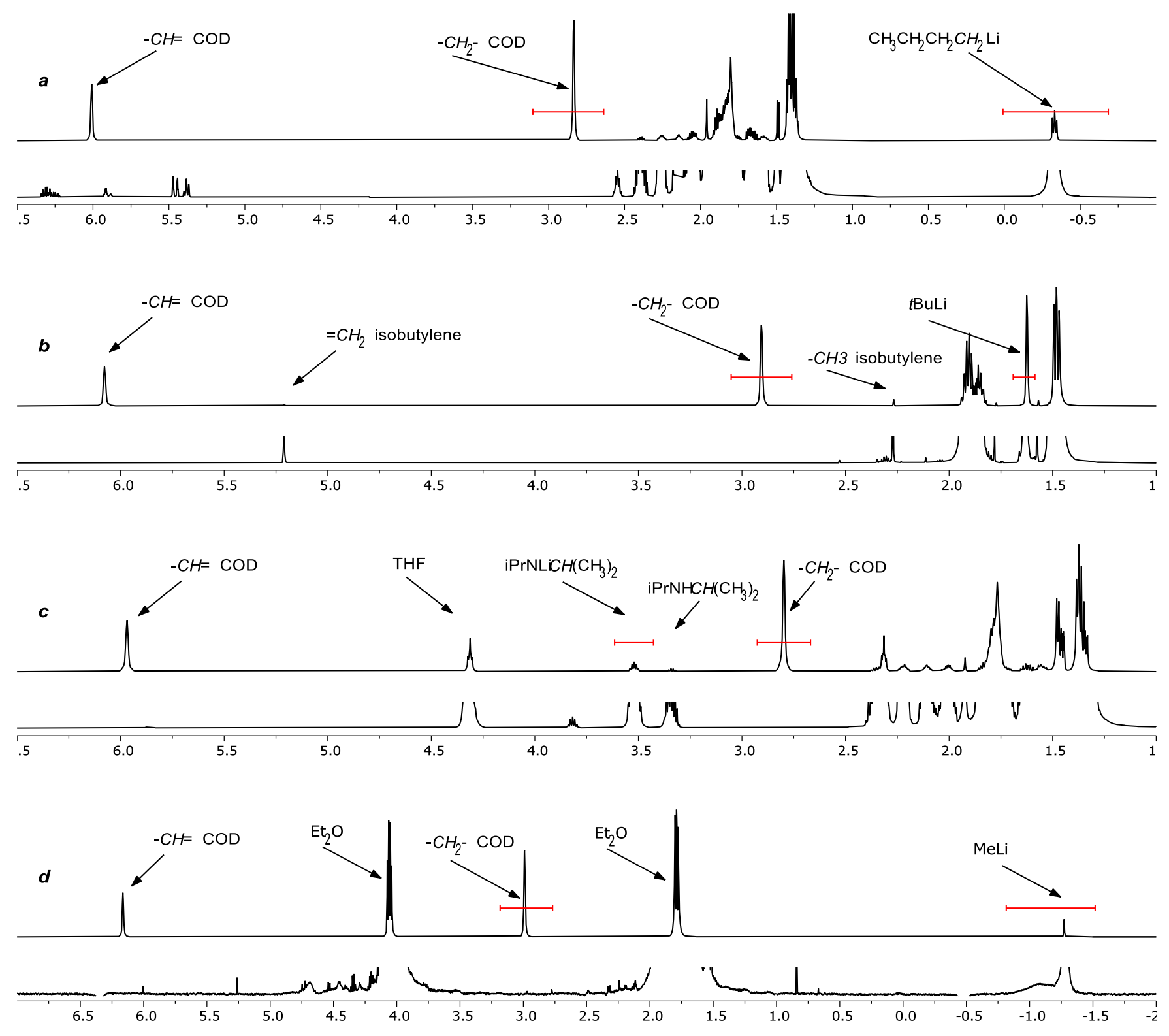

Figure 1 (continued)
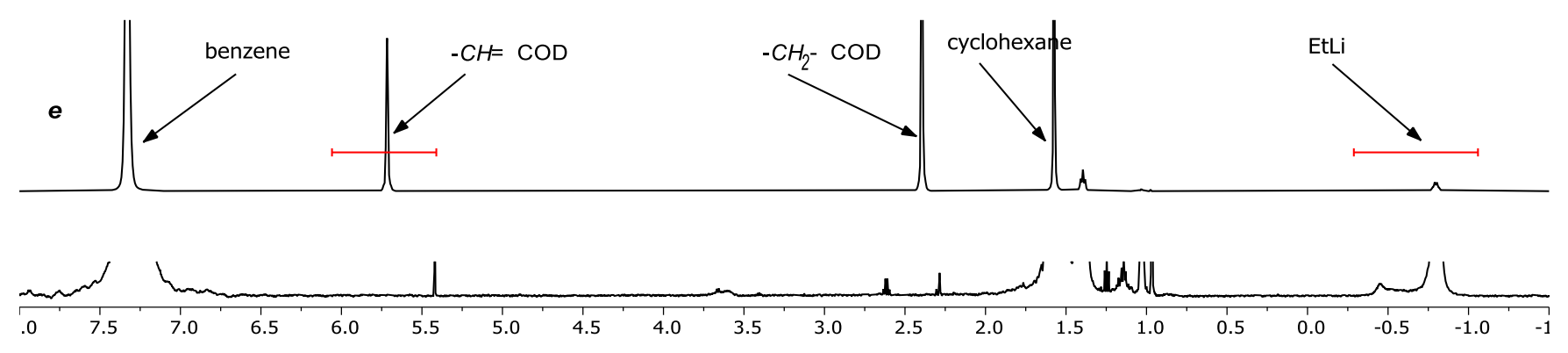

Figure S1. Proton spectra (with ${ }^{13} \mathrm{C}$ decoupling) of the organo-metal reagents solutions: a) $n$-butyllithum in hexanes; b) $t$ butyllithum in pentane; c) lithium diisopropylamide in THF/hexanes; d) methyllithium in diethyl ether; e) ethyllithium in benzene/cyclohexane. For each reagent solution, the top spectrum is of the sample used for determining the concentration using COD as internal reference. The integral regions used for calculation are marked in red. The bottom spectrum is of the neat solution used to determine the concentration using water as external reference. The intensity was adjusted for the signals of the impurities, to identify regions free of overlap. 

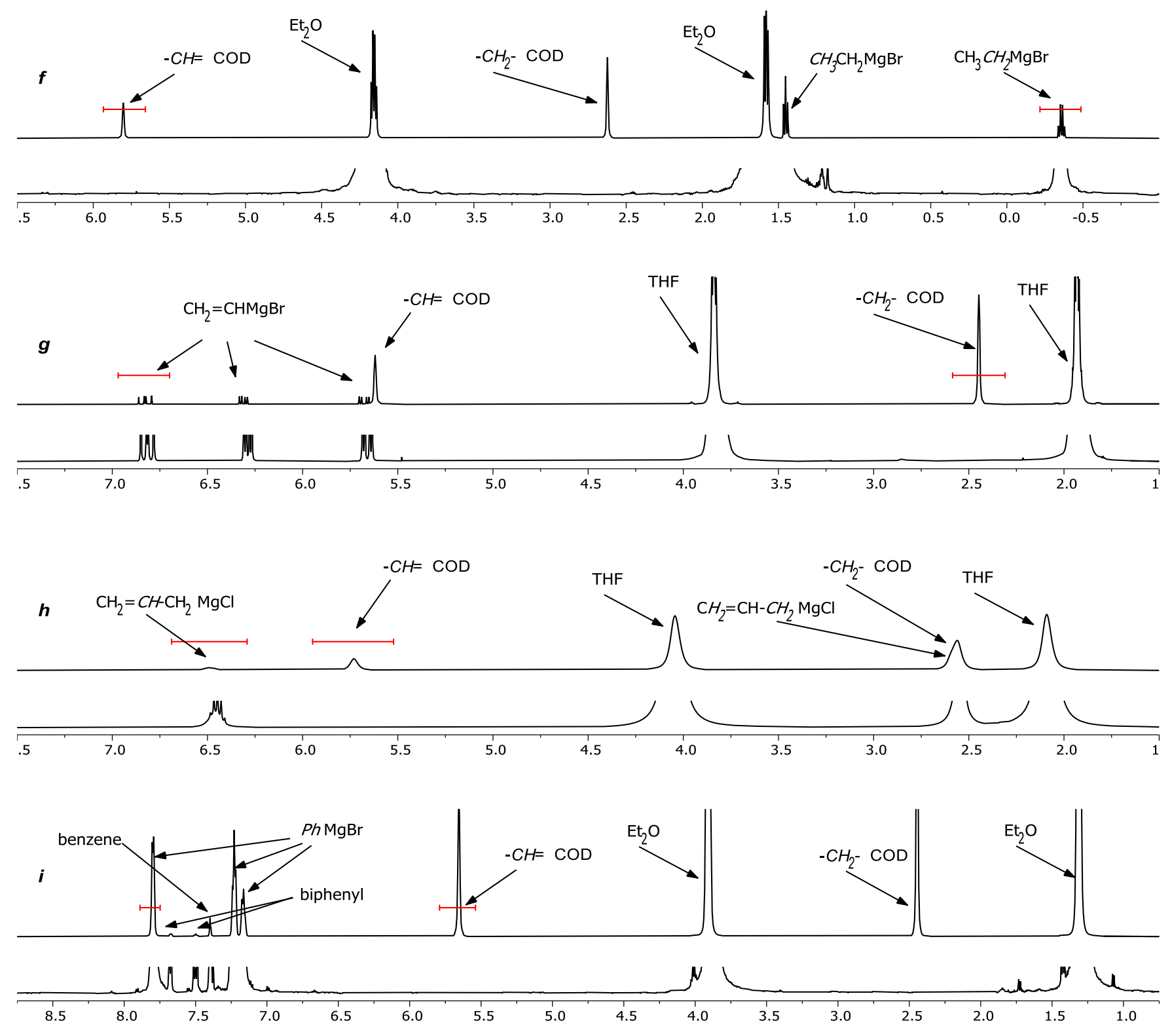

Figure S1 (continued). Proton spectra (with ${ }^{13} \mathrm{C}$ decoupling) of the organo-metal reagents solutions: f) ethylmagnesium bromide in diethyl ether; g) vinylmagnesium bromide in THF; h) allylmagnesium chloride in THF; i) phenylmagnesium bromide in diethyl ether. For each reagent solution, the top spectrum is of the sample used for determining the concentration using COD as internal reference. The integral regions used for calculation are marked in red. The bottom spectrum is of the neat solution used to determine the concentration using water as external reference. The intensity was adjusted for the signals of the impurities, to identify regions free of overlap. 
Table S1. Concentrations of neat solvents measured using water as external reference [exp.] vs. concentrations calculated from molar weight and density [calc.]. 01p is the chemical shift of the signal used for shimming, e.g. $1.38 \mathrm{ppm}$ for hexanes.

\begin{tabular}{|c|c|c|c|c|c|c|}
\hline compound & $\begin{array}{l}01 \mathrm{p} \\
(\mathrm{ppm})\end{array}$ & $\begin{array}{l}\text { density } \\
(\mathrm{g} / \mathrm{ml})\end{array}$ & $\begin{array}{l}\text { MW } \\
\text { (g/mol) }\end{array}$ & [calc.] & [exp.] & $\%$ err \\
\hline acetone & 3.09 & 0.7845 & 58.08 & 13.51 & 13.37 & -1.0 \\
\hline acetonitrile & 2.80 & 0.7900 & 41.05 & 19.24 & 19.09 & -0.8 \\
\hline benzene & 7.15 & 0.8765 & 78.11 & 11.22 & 11.08 & -1.3 \\
\hline chloroform a & 7.26 & 1.4890 & 119.37 & 12.47 & 12.52 & 0.4 \\
\hline cyclohexane & 1.87 & 0.7740 & 84.16 & 9.20 & 9.18 & -0.2 \\
\hline diethylether a & 1.85 & 0.7134 & 74.12 & 9.62 & 9.59 & -0.4 \\
\hline dioxane & 4.07 & 1.0330 & 88.11 & 11.72 & 11.67 & -0.4 \\
\hline DMF & 8.54 & 0.9480 & 73.10 & 12.97 & 12.84 & -1.0 \\
\hline DMSO & 3.09 & 1.1004 & 78.13 & 14.08 & 14.01 & -0.5 \\
\hline ethanol & 1.72 & 0.7893 & 46.07 & 17.13 & 17.30 & 1.0 \\
\hline isopropanol & 1.60 & 0.7860 & 60.10 & 13.08 & 13.23 & 1.2 \\
\hline methanol & 4.08 & 0.7920 & 32.04 & 24.72 & 24.62 & -0.4 \\
\hline methylene chloride a & 5.51 & 1.3266 & 84.93 & 15.62 & 15.67 & 0.4 \\
\hline nitromethane & 5.60 & 1.1371 & 61.04 & 18.63 & 18.39 & -1.3 \\
\hline pentane & 1.53 & 0.6262 & 72.151 & 8.68 & 8.58 & -1.1 \\
\hline pyridine & 8.71 & 0.9819 & 79.10 & 12.41 & 12.41 & -0.1 \\
\hline 1,1,2,2-tetrachloroethane a & 5.52 & 1.5900 & 167.80 & 9.48 & 9.51 & 0.4 \\
\hline tetrahydrofurane ${ }^{a}$ & 2.09 & 0.8876 & 72.11 & 12.31 & 12.22 & -0.7 \\
\hline toluene & 2.14 & 0.8621 & 92.14 & 9.36 & 9.30 & -0.6 \\
\hline trifluorotoluene & 7.20 & 1.1900 & 146.11 & 8.14 & 8.07 & -0.9 \\
\hline water & 4.34 & 0.9970 & 18.01 & 55.35 & refere & \\
\hline
\end{tabular}

a) these samples were spiked with chromium acetylacetonate for faster relaxation. 
Table S2. Average and standard deviation of the concentration neat solvents using water as external reference.

\begin{tabular}{|c|c|c|c|c|c|c|c|c|c|c|}
\hline compound & tube & $\mathrm{Tf}$ a & run 1 & run 2 & run 3 & run 4 & run 5 & average & Std. Dev. & \% Std. Dev. \\
\hline acetone & 8 & 0.9401 & 14.111 & 14.263 & 14.248 & 14.294 & 14.205 & 14.224 & 0.063 & 0.4 \\
\hline acetonitrile & 10 & 0.9423 & 20.236 & 20.25 & 20.244 & 20.288 & 20.274 & 20.258 & 0.019 & 0.1 \\
\hline benzene & 3 & 0.9402 & 11.773 & 11.788 & 11.790 & 11.763 & 11.807 & 11.784 & 0.015 & 0.1 \\
\hline chloroform & 10 & 0.9423 & 13.276 & 13.302 & 13.269 & 13.283 & 13.316 & 13.289 & 0.017 & 0.1 \\
\hline cyclohexane & 5 & 0.9396 & 9.725 & 9.813 & 9.741 & 9.789 & 9.779 & 9.769 & 0.032 & 0.3 \\
\hline diethylether & 1 & 0.9392 & 10.191 & 10.206 & 10.221 & 10.186 & 10.229 & 10.207 & 0.017 & 0.2 \\
\hline dioxane & 12 & 0.9868 & 11.823 & 11.841 & 11.829 & 11.804 & 11.843 & 11.828 & 0.014 & 0.1 \\
\hline $\mathrm{DMF}$ & 7 & 1.0033 & 12.806 & 12.807 & 12.814 & 12.772 & 12.808 & 12.801 & 0.015 & 0.1 \\
\hline DMSO & 6 & 0.9405 & 14.828 & 14.996 & 14.870 & 14.926 & 14.888 & 14.902 & 0.057 & 0.4 \\
\hline ethanol & 2 & 0.9412 & 18.346 & 18.463 & 18.366 & 18.410 & 18.302 & 18.377 & 0.055 & 0.3 \\
\hline isopropanol & 3 & 0.9402 & 14.011 & 14.119 & 14.101 & 14.095 & 14.054 & 14.076 & 0.039 & 0.3 \\
\hline methanol & 13 & 0.9945 & 24.724 & 24.746 & 24.769 & 24.720 & 24.799 & 24.752 & 0.029 & 0.1 \\
\hline methylene chloride & 9 & 0.9440 & 16.614 & 16.629 & 16.579 & 16.583 & 16.619 & 16.605 & 0.020 & 0.1 \\
\hline nitromethane & 6 & 0.9405 & 19.535 & 19.555 & 19.528 & 19.546 & 19.596 & 19.552 & 0.024 & 0.1 \\
\hline pentane & 4 & 0.9399 & 9.123 & 9.132 & 9.137 & 9.126 & 9.141 & 9.132 & 0.007 & 0.1 \\
\hline pyridine & 11 & 1.0007 & 12.347 & 12.405 & 12.375 & 12.447 & 12.421 & 12.399 & 0.035 & 0.3 \\
\hline 1,1,2,2-tetrachloroethane & 4 & 0.9399 & 10.077 & 10.153 & 10.130 & 10.109 & 10.116 & 10.117 & 0.025 & 0.2 \\
\hline tetrahydrofurane & 11 & 1.0007 & 12.211 & 12.203 & 12.196 & 12.208 & 12.230 & 12.210 & 0.011 & 0.1 \\
\hline toluene & 5 & 0.9396 & 9.895 & 9.898 & 9.902 & 9.881 & 9.902 & 9.896 & 0.008 & 0.1 \\
\hline trifluorotoluene & 1 & 0.9392 & 8.569 & 8.587 & 8.594 & 8.580 & 8.625 & 8.591 & 0.019 & 0.2 \\
\hline
\end{tabular}

a) tube factor determined for each tube by averaging five measurements of the concentration of water. The average value of the measured concentration was multiplied by the tube factor to give the experimental concentration in Table S1. 
Table S3. Average and standard deviation of the concentration of $n$-BuLi $2.5 \mathrm{M}$ in hexanes: [COD] molar concentration determined using 1,5-cyclooctadiene as internal reference; ${ }^{1}$ [water] determined using a water sample as external reference; [titr.1] determined by titration with $l$-menthol using $2,2^{\prime}$-bipyridine as an indicator; ${ }^{1}$ [titr.2] determined by titration with 2hydroxybenzaldehyde phenylhydrazone as an indicator. ${ }^{2}$

\begin{tabular}{llllllll}
\hline $\begin{array}{l}\text { sample } \\
\text { no. }\end{array}$ & $\mathrm{mg}$ COD & $\mathrm{ml} n$-BuLi & $\begin{array}{l}\text { mol ratio } \\
n \text {-BuLi/COD }\end{array}$ & [CODi] & [water] & [titr. 1] & [titr. 2] \\
\hline 1 & 134.6 & 0.67 & 1.326 & 2.462 & 2.529 & 2.64 & 2.40 \\
2 & 138.3 & 0.71 & 1.361 & 2.451 & 2.508 & 2.64 & 2.33 \\
3 & 147.5 & 0.68 & 1.259 & 2.524 & 2.489 & 2.64 & 2.33 \\
4 & 158.6 & 0.67 & 1.128 & 2.468 & 2.521 & 2.64 & 2.36 \\
5 & 161.2 & 0.70 & 1.157 & 2.464 & 2.519 & 2.68 & 2.31 \\
\hline & & & 2.474 & 2.513 & 2.648 & 2.346 \\
& & Average & & 0.026 & 0.014 & 0.016 & 0.031 \\
\hline
\end{tabular}

Table S4. Average and standard deviation of the concentration of $t$-BuLi 1.7 M in pentane: [COD] molar concentration determined using 1,5-cyclooctadiene as internal reference; ${ }^{1}$ [water] determined using a water sample as external reference; [titr.1] determined by titration with $l$-menthol using $2,2^{\prime}$-bipyridine as an indicator; ${ }^{1}$ [titr.2] determined by titration with 2hydroxybenzaldehyde phenylhydrazone as an indicator. ${ }^{2}$

\begin{tabular}{llllllll}
\hline $\begin{array}{l}\text { sample } \\
\text { no. }\end{array}$ & mg COD & ml $t$-BuLi & $\begin{array}{l}\text { mol ratio } \\
t \text {-BuLi/COD }\end{array}$ & [COD] & [water] & [titr. 1] & [titr. 2] \\
\hline 1 & 133.1 & 0.69 & 0.896 & 1.598 & 1.705 & 1.76 & 1.51 \\
2 & 141.3 & 0.71 & 0.889 & 1.636 & 1.695 & 1.76 & 1.56 \\
3 & 144.6 & 0.68 & 0.841 & 1.654 & 1.693 & 1.75 & 1.55 \\
4 & 144.9 & 0.73 & 0.870 & 1.597 & 1.657 & 1.73 & 1.56 \\
5 & 151.1 & 0.70 & 0.779 & 1.554 & 1.712 & 1.75 & 1.58 \\
\hline & & & 1.608 & 1.692 & 1.750 & 1.552 \\
& & Average & & 0.035 & 0.019 & 0.011 & 0.023 \\
\hline
\end{tabular}

Table S5. Average and standard deviation of the concentration of LDA $1 \mathrm{M}$ in THF/hexanes: [COD] molar concentration determined using 1,5-cyclooctadiene as internal reference ${ }^{1}$ [water] determined using a water sample as external reference; [titr.1] determined by titration with $l$-menthol using 2,2'-bipyridine as an indicator; ${ }^{1}$ [titr.2] determined by titration with 2hydroxybenzaldehyde phenylhydrazone as an indicator. ${ }^{2}$

\begin{tabular}{llllllll}
\hline $\begin{array}{l}\text { sample } \\
\text { no. }\end{array}$ & mg COD & ml LDA & $\begin{array}{l}\text { mol ratio } \\
\text { LDA/COD }\end{array}$ & [COD] & [water] & [titr. 1] & [titr. 2] \\
\hline 1 & 142.6 & 0.67 & 0.444 & 0.873 & 0.890 & 1.03 & 0.95 \\
2 & 147.7 & 0.68 & 0.436 & 0.876 & 0.906 & 1.04 & 0.98 \\
3 & 137.7 & 0.65 & 0.441 & 0.863 & 0.903 & 1.04 & 0.93 \\
4 & 139.6 & 0.64 & 0.431 & 0.870 & 0.894 & 1.07 & 0.95 \\
5 & 137.5 & 0.72 & 0.496 & 0.876 & 0.902 & 1.04 & 0.96 \\
\hline & & & 0.871 & 0.899 & 1.044 & 0.954 \\
& & Average & & 0.005 & 0.006 & 0.014 & 0.016 \\
\hline
\end{tabular}


Table S6. Average and standard deviation of the concentration of MeLi 1.6M in $\mathrm{Et}_{2} \mathrm{O}$ : [COD] molar concentration determined using 1,5-cyclooctadiene as internal reference; ${ }^{1}$ [water] determined using a water sample as external reference; [titr.1] determined by titration with $l$-menthol using $2,2^{\prime}$-bipyridine as an indicator; ${ }^{1}$ [titr.2] determined by titration with 2hydroxybenzaldehyde phenylhydrazone as an indicator. ${ }^{2}$

\begin{tabular}{llllllll}
\hline $\begin{array}{l}\text { sample } \\
\text { no. }\end{array}$ & mg COD & ml MeLi & $\begin{array}{l}\text { mol ratio } \\
\text { MeLi/COD }\end{array}$ & [COD] & [water] & [titr. 1] & [titr. 2] \\
\hline 1 & 158.7 & 0.66 & 0.255 & 0.567 & 0.591 & 0.64 & 0.60 \\
2 & 169.8 & 0.67 & 0.242 & 0.566 & 0.582 & 0.63 & 0.60 \\
3 & 150.8 & 0.61 & 0.232 & 0.530 & 0.583 & 0.63 & 0.60 \\
4 & 177.9 & 0.67 & 0.224 & 0.549 & 0.589 & 0.64 & 0.62 \\
5 & 166.8 & 0.58 & 0.203 & 0.539 & 0.591 & 0.64 & 0.61 \\
\hline & & & 0.550 & 0.587 & 0.636 & 0.606 \\
& & Average & & 0.015 & 0.004 & 0.005 & 0.008 \\
\hline
\end{tabular}

Table S7. Average and standard deviation of the concentration of EtLi $0.5 \mathrm{M}$ in benzene/cyclohexane: [COD] molar concentration determined using 1,5-cyclooctadiene as internal reference; ${ }^{1}$ [water] determined using a water sample as external reference; [titr.1] determined by titration with $l$-menthol using 2,2'-bipyridine as an indicator; ${ }^{1}$ [titr.2] determined by titration with 2hydroxybenzaldehyde phenylhydrazone as an indicator. ${ }^{2}$

\begin{tabular}{llllllll}
\hline $\begin{array}{l}\text { sample } \\
\text { no. }\end{array}$ & mg COD & ml EtLi & $\begin{array}{l}\text { mol ratio } \\
\text { EtLi/COD }\end{array}$ & [COD] & [water] & [titr. 1] & [titr. 2] \\
\hline 1 & 147.7 & 0.67 & 0.265 & 0.541 & 0.532 & 0.61 & 0.54 \\
2 & 149.2 & 0.68 & 0.262 & 0.532 & 0.533 & 0.61 & 0.55 \\
3 & 156.1 & 0.67 & 0.249 & 0.537 & 0.520 & 0.60 & 0.54 \\
4 & 147.6 & 0.67 & 0.262 & 0.533 & 0.523 & 0.60 & 0.55 \\
5 & 150.5 & 0.63 & 0.239 & 0.527 & 0.535 & 0.60 & 0.55 \\
\hline & & & 0.534 & 0.529 & 0.604 & 0.546 \\
& & Average & & 0.005 & 0.006 & 0.005 & 0.005 \\
\hline
\end{tabular}

Table S8. Average and standard deviation of the concentration of EtMgBr 3M in Et20: [COD] molar concentration determined using 1,5-cyclooctadiene as internal reference; ${ }^{1}$ [water] determined using a water sample as external reference; [titr.1] determined

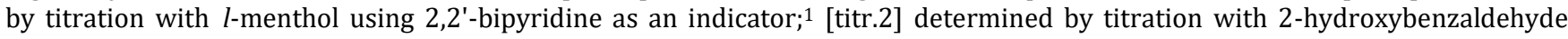
phenylhydrazone as an indicator. ${ }^{2}$

\begin{tabular}{llllllll}
\hline $\begin{array}{l}\text { sample } \\
\text { no. }\end{array}$ & mg COD & $\begin{array}{l}\mathrm{ml} \\
\text { EtMgBr }\end{array}$ & $\begin{array}{l}\text { mol ratio } \\
\text { EtMgBr/COD }\end{array}$ & [COD] & [water] & [titr. 1] & [titr. 2] \\
\hline 1 & 134.6 & 0.680 & 1.671 & 3.058 & 3.212 & 3.200 & 2.850 \\
2 & 144.4 & 0.710 & 1.621 & 3.048 & 3.201 & 3.200 & 2.940 \\
3 & 149.4 & 0.700 & 1.563 & 3.084 & 3.191 & 3.170 & 2.920 \\
4 & 166.1 & 0.720 & 1.434 & 3.059 & 3.180 & 3.110 & 2.880 \\
5 & 165.4 & 0.730 & 1.472 & 3.083 & 3.209 & 3.140 & 2.900 \\
\hline & & Average & & 3.066 & 3.199 & 3.164 & 2.898 \\
& & Std. Dev. & & 0.015 & 0.012 & 0.035 & 0.031 \\
\hline
\end{tabular}


Table S9. Average and standard deviation of the concentration of $\mathrm{VnMgBr} 1 \mathrm{M}$ in THF: [COD] molar concentration determined using 1,5-cyclooctadiene as internal reference; ${ }^{1}$ [water] determined using a water sample as external reference; [titr.1] determined by titration with $l$-menthol using 2,2'-bipyridine as an indicator; ${ }^{1}$ [titr.2] determined by titration with 2-hydroxybenzaldehyde phenylhydrazone as an indicator. ${ }^{2}$

\begin{tabular}{llllllll}
\hline $\begin{array}{l}\text { sample } \\
\text { no. }\end{array}$ & mg COD & $\begin{array}{l}\text { ml } \\
\text { VnMgBr }\end{array}$ & $\begin{array}{l}\text { mol ratio } \\
\text { VnMgBr/COD }\end{array}$ & [COD] & [water] & [titr. 1] & [titr. 2] \\
\hline 1 & 115.3 & 0.63 & 0.542 & 0.917 & 0.925 & 1.11 & 1.00 \\
2 & 125.7 & 0.65 & 0.509 & 0.910 & 0.918 & 1.11 & 1.00 \\
3 & 119.7 & 0.69 & 0.567 & 0.909 & 0.907 & 1.11 & 1.03 \\
4 & 121.2 & 0.65 & 0.539 & 0.930 & 0.926 & 1.09 & 0.99 \\
5 & 112.4 & 0.64 & 0.577 & 0.937 & 0.920 & 1.08 & 0.98 \\
\hline & & Average & & 0.920 & 0.919 & 1.100 & 1.000 \\
& & Std. Dev. & & 0.011 & 0.007 & 0.013 & 0.016 \\
\hline
\end{tabular}

Table S10. Average and standard deviation of the concentration of AllylMgCl 2M in THF: [COD] molar concentration determined using 1,5-cyclooctadiene as internal reference; ${ }^{1}$ [water] determined using a water sample as external reference; [titr.1] determined by titration with $l$-menthol using 2,2'-bipyridine as an indicator; ${ }^{1}$ [titr.2] determined by titration with 2 -hydroxybenzaldehyde phenylhydrazone as an indicator. ${ }^{2}$

\begin{tabular}{llllllll}
\hline $\begin{array}{l}\text { sample } \\
\text { no. }\end{array}$ & mg COD & $\begin{array}{l}\text { ml } \\
\text { AlMgCl }\end{array}$ & $\begin{array}{l}\text { mol ratio } \\
\text { AlMgCl/COD }\end{array}$ & [COD] & [water] & [titr. 1] & [titr. 2] \\
\hline 1 & 117.9 & 0.65 & 1.392 & 2.334 & 2.230 & 2.45 & 2.20 \\
2 & 139.1 & 0.69 & 1.275 & 2.376 & 2.250 & 2.43 & 2.28 \\
3 & 147.7 & 0.71 & 1.207 & 2.321 & 2.280 & 2.41 & 2.15 \\
4 & 133.2 & 0.69 & 1.309 & 2.336 & 2.180 & 2.38 & 2.18 \\
5 & 156.1 & 0.70 & 1.147 & 2.364 & 2.301 & 2.34 & 2.16 \\
\hline & & Average & & 2.346 & 2.248 & 2.402 & 2.194 \\
& & Std. Dev. & & 0.021 & 0.042 & 0.039 & 0.046 \\
\hline
\end{tabular}

Table S11. Average and standard deviation of the concentration of PhMgBr 3M in Et 20 : [COD] molar concentration determined using 1,5-cyclooctadiene as internal reference; ${ }^{1}$ [water] determined using a water sample as external reference; [titr.1] determined by titration with $l$-menthol using 2,2'-bipyridine as an indicator; ${ }^{1}$ [titr.2] determined by titration with 2-hydroxybenzaldehyde phenylhydrazone as an indicator. ${ }^{2}$

\begin{tabular}{llllllll}
\hline $\begin{array}{l}\text { sample } \\
\text { no. }\end{array}$ & mg COD & $\begin{array}{l}\mathrm{ml} \\
\mathrm{PhMgBr}\end{array}$ & $\begin{array}{l}\text { mol ratio } \\
\mathrm{PhMgBr} / \mathrm{COD}\end{array}$ & [COD] & [water] & [titr. 1] & [titr. 2] \\
\hline 1 & 131.0 & 0.71 & 1.740 & 2.968 & 2.990 & 3.14 & 2.78 \\
2 & 128.5 & 0.70 & 1.771 & 3.005 & 3.028 & 3.03 & 2.78 \\
3 & 125.8 & 0.68 & 1.728 & 2.955 & 3.050 & 3.33 & 2.81 \\
4 & 134.4 & 0.71 & 1.678 & 2.936 & 2.972 & 3.03 & 2.83 \\
5 & 138.9 & 0.70 & 1.634 & 2.997 & 3.022 & 2.97 & 2.79 \\
\hline & & Average & & 2.972 & 3.012 & 3.100 & 2.798 \\
& & Std. Dev. & & 0.026 & 0.028 & 0.127 & 0.019 \\
\hline
\end{tabular}


Table S12. Measured concentration of dioxane in toluene in samples prepared by subsequent dilutions of dioxane with an equal volume of toluene.

\begin{tabular}{rr}
\hline [dioxane] $]_{\text {calculated }}$ & [dioxane] $]_{\text {measured }}$ \\
\hline 5.8600 & 5.8260 \\
2.9300 & 2.9206 \\
1.4650 & 1.4570 \\
0.7325 & 0.7290 \\
0.3663 & 0.3676 \\
0.1831 & 0.1792 \\
0.0916 & 0.0913 \\
0.0458 & 0.0463 \\
0.0229 & 0.0225 \\
0.0114 & 0.0109 \\
\hline
\end{tabular}

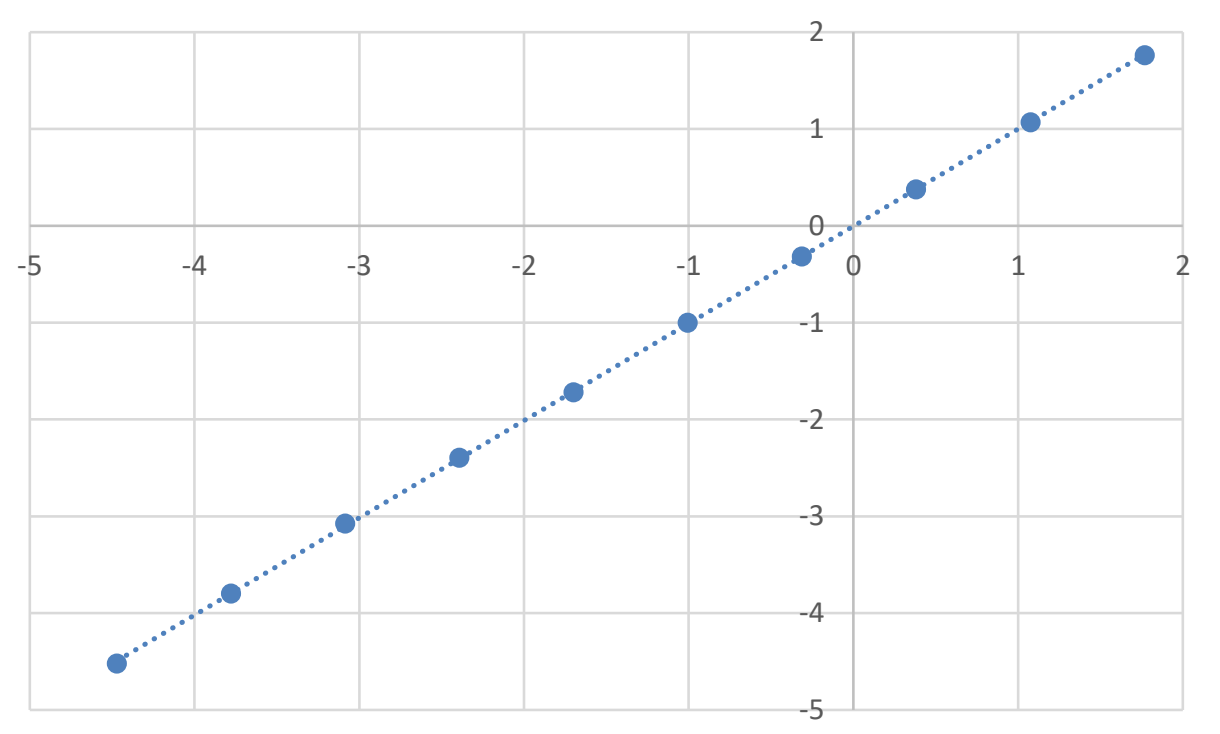

Figure S2. Plot of data in Table S12: $\log \left([\text { dioxane }]_{\text {measured }}\right)$ vs. $\log \left([\text { dioxane }]_{\text {calculated }}\right)$.

\section{References}

(1) Hoye, T. R.; Eklov, B. M.; Voloshin, M. No-D NMR Spectroscopy as a Convenient Method for Titering Organolithium (RLi), RMgX, and LDA Solutions. Org. Lett. 2004, 6 (15), 2567-2570. https://doi.org/10.1021/ol049145r.

(2) Love, B. E; Jones, E. G. The Use of Salicylaldehyde Phenylhydrazone as an Indicator for the Titration of Organometallic Reagents. J. Org. Chem. 1999, 64 (10), 3755-3756. https://doi.org/10.1021/jo982433e. 